\title{
Criptógamos do Parque Estadual das Fontes do Ipiranga, São Paulo, SP. Algas, 27: Euglenophyceae (famílias Petalomonadaceae e Scytomonadaceae)
}

\author{
Carlos Eduardo de Mattos Bicudo ${ }^{1}$
}

Recebido: 02.09.2009; aceito: 13.05.2010

\begin{abstract}
Cryptogams of the "Parque Estadual das Fontes do Ipiranga", São Paulo, SP. Algae, 27: Euglenophyceae (Petalomonadaceae e Scytomonadaceae)). Taxonomic survey of representatives of families Petalomonadaceae and Scytomonadaceae (Euglenophyceae) in the Parque Estadual das Fontes do Ipiranga, São Paulo, Brazil. One genus of Petalomonadaceae (Petalomonas) with two species and one of Scytomonadaceae (Scytomonas) with a single species were identified. All species were collected from a single locality each.
\end{abstract}

Key words: Brazil, Euglenophyceae, Petalomonas, Scytomonas

RESUMO - (Criptógamos do Parque Estadual das Fontes do Ipiranga, São Paulo, SP. Algas. 27: Euglenophyceae (Petalomonadaceae e Scytomonadaceae)). Levantamento florístico dos representantes das famílias Petalomonadaceae e Scytomonadaceae (Euglenophyceae) do Parque Estadual das Fontes do Ipiranga, São Paulo, Brasil. Um gênero de Petalomonadaceae (Petalomonas) com duas espécies e um de Scytomonadaceae (Scytomonas) com apenas uma espécie foram identificados. Todas as três espécies ocorreram somente em uma localidade cada uma.

Palavras-chave: Brasil, Euglenophyceae, Petalomonas, Scytomonas

\section{Introdução}

Dois trabalhos apenas reúnem o conhecimento atual das famílias Petalomonadaceae e Scytomonadaceae no PEFI, Parque Estadual das Fontes do Ipiranga. No primeiro deles, Skvortzov (1968) documentou a ocorrência de cinco espécies de Petalomonas (P.rotante Skvortzov, P. limae Skvortzov, P. stellata Skvortzov, $P$. ovata Skvortzov e $P$. colemanii Skvortzov) em ambientes da cidade de São Paulo, descrevendo todas como novidades para a Ciência. Duas dessas espécies foram coletadas no PEFI, quais sejam: $P$. stellata Skvortzov e $P$. ovata Skvortzov. O outro trabalho é de Bicudo \& Bicudo (1987), que relacionaram a presença de Scytomonas major (Berliner) Lemmermann no PEFI, descrevendo e ilustrando o material estudado.

\section{Material e métodos}

O presente trabalho foi quase que inteiramente baseado em material da literatura. Exceto Scytomonas major (Berliner) Lemmermann, que foi coletada diversas vezes, entretanto todas no mesmo local (hidrofitotério do Jardim Botânico de São Paulo), as demais amostragens realizadas na área do PEFI jamais contiveram material de Petalomonadaceae ou de Scytomonadaceae. Acrescente-se que Scytomonas major (Berliner) Lemmermann não pode ser fixada pelos processos usuais e, portanto, não pôde ser preservada, o que quer dizer que não há amostra dessa espécie depositada no Herbário Científico do Estado "Maria Eneyda P. Kauffmann Fidalgo" (SP) do Instituto de Botânica da Secretaria do Meio Ambiente

1. Instituto de Botânica, Caixa Postal 3005, 01061-970 São Paulo, SP, Brasil. cbicudo@terra.com.br 
do Estado de São Paulo. Os métodos utilizados para coletar e estudar o material estão em Bicudo \& Menezes (2006).

Para a pronta localização das famílias neste trabalho, elas aparecem relacionadas em ordem alfabética crescente, inclusive as duas espécies de Petalomonas dentro do gênero. As espécies que constam unicamente da literatura, isto é, que jamais foram reencontradas durante o presente levantamento tiveram seus nomes citados nas chaves de identificação e no texto precedidos por um asterisco.

O sistema de classificação adotado foi o de Bourrelly (1970), por se tratar do único que inclui, praticamente, todos os gêneros até então conhecidos e classificados segundo critérios uniformemente aplicados a todo o universo dos gêneros nele contidos.

\section{Resultados e Discussão}

Os dois gêneros presentemente identificados para o PEFI têm a seguinte situação sistemática:

Divisão Euglenophyta

Classe Euglenophyceae

Ordem Euglenales

Família Petalomonadaceae

Petalomonas

Família Scytomonadaceae

Scytomonas

\section{PETALOMONADACEAE}

Indivíduos unicelulares, incolores, de hábito isolado e vida livre, ativamente móveis na fase vegetativa e que possuem dois flagelos situados anteriormente na célula. Um deles ou os dois emergem do reservatório. O flagelo nadador vai sempre voltado para frente enquanto o indivíduo se desloca. A célula é, em geral, comprimida bilateralmente, de modo que sua seção transversal varia de elíptica a poligonal. A película é sempre um tanto espessa, não possibilitando a metabolia, ou seja, a célula mantém a forma fixa enquanto se desloca. A película pode ser decorada com costelas ou carenas longitudinais, que ora são retas ora torcidas em hélice. A nutrição é do tipo fagotrófica ou, mais raramente, osmotrófica.

Os gêneros não-pigmentados são, de modo geral entre as Euglenophyceae, muito menos conhecidos do que os pigmentados e as Petalomonadaceae não constituem exceção. Huber-Pestalozzi (1955) ainda é a melhor referência para identificação dos gêneros e espécies classificados nesta família.
Petalomonas Dujardin emend. Stein

Indivíduos unicelulares de vida livre e hábito solitário livre-natante. A forma da célula pode ser ovóide, fusiforme, triangular, etc. Em corte óptico transversal, a célula é mais ou menos comprimida. A película é relativamente rígida e pode apresentar cristas situadas paralelas umas às outras, tanto retas, longitudinalmente dispostas, quanto torcidas em hélice. Ocorrem dois flagelos, dos quais o longo ultrapassa o limite do reservatório, dirigindo-se sempre para frente enquanto a célula nada, e o curto é um simples coto, que jaz vibrando dentro do reservatório. A abertura do reservatório é subapical, razão pela qual a célula aparece bilateralmente assimétrica em vista frontal.

Chave para as espécies de Petalomonas

1. Célula obovada ....................................* P. ovata

1. Célula ovóide a fusiforme ...................* P. stellata

* P. ovata Skvortzov, Acta Botanica Venezuelica 1(14): 295, fig. 5. 1968.

Figura 1

Indivíduo unicelular, solitário, livre-natante, não-metabólico; célula obovada, pólo anterior arredondado-truncado, pólo posterior acuminadoarredondado, 18,5-37 $\mu \mathrm{m}$ compr., 9-18 $\mu \mathrm{m}$ larg.; seção transversal 4-angular, ângulos arredondados, pouco proeminentes, margem entre os ângulos moderadamente curva; película extremamente delgada, rígida, 4 carenas pouco salientes; flagelo aparente 1, anterior, 1 vez o comprimento da célula; grânulos de paramido numerosos, esféricos, pequenos, alinhados em toda a periferia da célula.

Hábitat: planctônico.

Skvortzov (1968) não fez referência ao segundo flagelo nem à existência de um reservatório nesta espécie.

O material estudado foi coletado pelo próprio B.V. Skvortzov, porém, a localização do sítio de proveniência da amostra é bastante vaga e diz apenas, traduzindo para o português: em água parada, entre Salvinia auriculata Aublet.

* P. stellata Skvortzov, Acta Botanica Venezuelica 1(1-4): 295, fig. 4. 1968.

Figura 2

Indivíduo unicelular, solitário, livre-natante, não-metabólico; célula ovóide a fusiforme, pólo anterior acuminado, pontiagudo, pólo posterior 


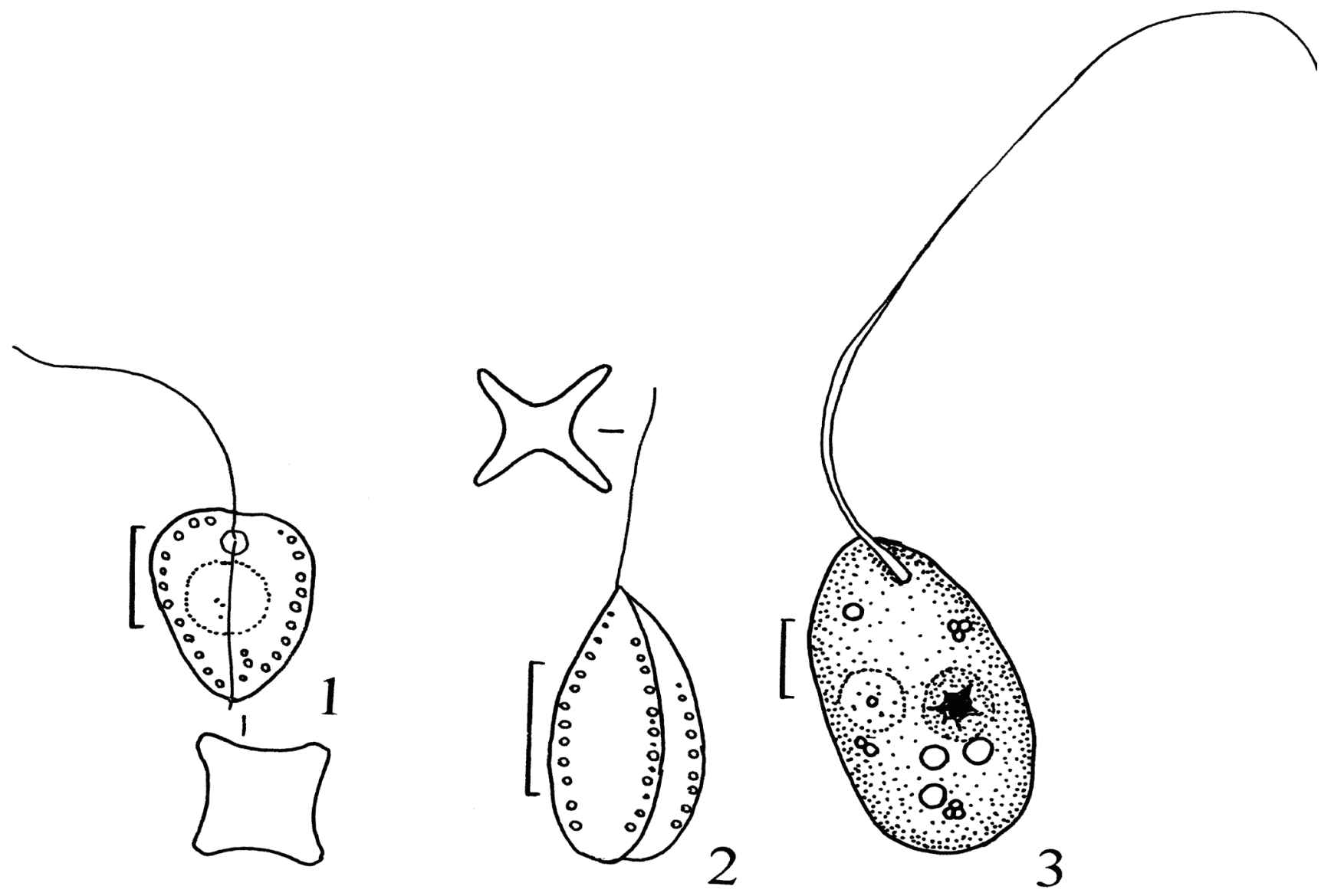

Figuras 1-3. Espécies das famílias Petalomonadaceae e Scytomonadaceae. 1. Petalomonas ovata (Skvortzov 1968). 1a. Seção transversal da célula. 2. Petalomonas stellata (Skvortzov 1968). 2a. Seção transversal da célula. 3. Scytomonas major (Bicudo \& Bicudo 1987). Barras das escala $=10 \mu \mathrm{m}$.

Figures 1-3. Species of families Petalomonadaceae and Scytomonadaceae. 1. Petalomonas ovata (Skvortzov 1968). 1a. Transversal section of cell. 2. Petalomonas stellata (Skvortzov 1968). 2a. Transversal section of cell. 3. Scytomonas major (Bicudo \& Bicudo 1987). Scale bar $=10 \mu \mathrm{m}$.

acuminado-arredondado, ca. 20,8 $\mu \mathrm{m}$ compr., ca. 9,6 $\mu \mathrm{m}$ larg.; seção transversal 4-angular, ângulos arredondados, bastante proeminentes, margem entre os ângulos acentuadamente curva, um tanto angular; película extremamente delgada, rígida, 4 carenas bastante proeminentes; flagelo aparente 1 , anterior, 1/2-2/3 do comprimento da célula; grânulos de paramido numerosos, pequenos, esféricos, alinhados na extremidade de cada carena.

Hábitat: planctônico.

Os materiais desta espécie e de P.ovata Skvortzov examinados por Skvortzov (1968) foram coletados por ele próprio de um corpo d'água praticamente parada contendo plantas de Salvinia auriculata Aublet. Como no caso anterior, a localização no PEFI do sítio de coleta é muito vaga e o material coletado nas duas ocasiões jamais foi fixado e preservado sob qualquer forma, o que quer dizer que não há espécime de qualquer uma delas no Herbário do Instituto de Botânica. Tampouco este material permite fixação e preservação.

Também como no material anterior, Skvortzov (1968) não fez referência ao segundo flagelo nem à existência de um reservatório nesta espécie.

\section{SCYTOMONADACEAE}

Indivíduos unicelulares, incolores, isolados, de vida livre e nadadores ativos na fase vegetativa. A célula pode ser elipsóide ou um pouco piriforme em vista frontal. O flagelo é único por indivíduo e sai anterior e subapicalmente na célula, do fundo de um reservatório. Este flagelo é razoavelmente grosseiro e 
vai sempre dirigido para frente enquanto o indivíduo se desloca. A película é suficientemente espessa para garantir a forma fixa (não-metabólica) dos indivíduos enquanto se deslocam. A seção transversal da célula é circular ou quase. A nutrição pode ser fagotrófica ou saprotrófica.

A família foi proposta por Mignot (1967) para incluir o gênero Scytomonas, por conta de seus representantes serem os únicos de todas as Euglenophyceae a possuir só um flagelo.

\section{Scytomonas Stein}

Indivíduos unicelulares ativamente móveis, nãometabólicos e de hábito isolado. A forma da célula em repouso pode ser elipsóide ou piriforme, com ambos os pólos amplamente arredondados. A seção transversal é praticamente circular. A película é lisa e espessa o suficiente para não permitir a metabolia. Ocorre só um flagelo por célula, grosseiro, inserido subapicalmente na célula, no fundo de um reservatório, que vai sempre dirigido para frente durante a natação. Estudos não muito recentes realizados por Mignot (1964) comprovaram a presença de um bastonete faringeano extremamente reduzido.

Estas algas vivem em águas fortemente poluídas por matéria orgânica e se nutrem por fagotrofismo e saprofitismo. Conforme Bourrelly (1970), Scytomonas major (Berliner) Lemmermann foi encontrada apenas no trato intestinal do lagarto verde, Lacerta viridis Gessner.

Reprodução sexuada do tipo isogâmico foi descrita por Dobell (1908). Contudo, conforme o próprio autor afirma, o único fato desse processo que foi estabelecido com absoluta certeza é a fusão dos gametas. A divisão do núcleo do zigoto ainda carece de esclarecimento. $\mathrm{O}$ zigoto permanece móvel no ambiente por certo tempo, mas a duração deste tempo também não consta em Dobell (1908).

Leedale (1967) colocou Scytomonas entre os gêneros de posição taxonômica duvidosa por necessitarem de mais estudos para definir, inclusive, se a alga é um flagelado euglenóide.

Uma única espécie foi identificada.

S. major (Berliner) Lemmermann in Pascher, Die Süsswasser-Flora Deutschlands, Österreich und der Schweiz 2: 168, fig. 333. 1913 三 Copromonas major Berliner, Archiv für Protistenkunde 15: 300. 1909. Figura 3

Indivíduo unicelular, solitário, livre-natante, não- metabólico; célula em repouso elipsóide alongada até suboblonga, pólos anterior e posterior amplamente arredondados, seção transversal circular ou quase, 40-45 $\mu \mathrm{m}$ compr., 20-25 $\mu \mathrm{m}$ larg.; flagelo único, ca. 2 vezes mais longo que o corpo da célula; estigma ausente; grãos de paramido não observados.

Hábitat: planctônico.

Todo o conhecimento desta espécie no Brasil está em Bicudo \& Bicudo (1987), que a identificou de material coletado no hidrofitotério do Jardim Botânico de São Paulo.

Bicudo \& Bicudo (1987) levantaram a hipótese de $S$. ovatum Silva ser um sinônimo heterotípico de $S$. major (Berliner) Lemmermann e afirmaram que a única diferença entre as duas espécies reside nas medidas da célula. Assim, S. ovatum Silva mede $50 \times 20 \mu \mathrm{m}$ e $S$. major (Berliner) Lemmermann praticamente a metade, isto é, ca. $20 \times$ ca. $8 \mu \mathrm{m}$. Os autores antes mencionados disseram ainda que S. major (Berliner) Lemmermann é uma espécie de ocorrência rara e que todo seu conhecimento provém apenas de sua descrição original em Berliner (1909), a qual foi posteriormente copiada por HuberPestalozzi (1955) e Starmach (1983). O único outro registro original da existência da espécie está em Bicudo \& Bicudo (1987).

Chave geral

1. Célula 1-flagelada; reservatório situado subapicalmente na célula

(Scytomonas) S. major

1. Célula 2-flagelada ( 1 extroverte o reservatório e o outro, muito curto, jaz no interior do reservatório); reservatório situado apicalmente na célula

(Petalomonas)

2. Célula obovada * P. ovata

2. Célula ovóide a fusiforme .............* ${ }^{*} P$. stellata

O inventário taxonômico das algas do Parque Estadual das Fontes do Ipiranga está baseado em um processo intensivo de coleta que já dura quase 40 anos. Provém também dos inúmeros trabalhos ecológicos realizados nos ambientes do PEFI. Apesar, entretanto, de todo esse esforço de coleta, nenhum material de Petalonemataceae foi reencontrado. Todo o conhecimento, portanto, das duas espécies de Petalomonas tratadas neste trabalho provém da literatura, ou seja, das descrições originais de cada espécie, isto é, dos únicos documentos disponíveis sobre cada uma. Nestas condições, os nomes dessas 
espécies constantes na literatura devem prevalecer até que seja coletado, material de cada uma e, um estudo mais profundo seja providenciado, propiciando-lhes um conhecimento mais detalhado e adequado.

Os representantes tanto de Petalomonadaceae quanto de Scytomonadaceae vivem emáguas fortemente poluídas por matéria orgânica. No caso específico de Scytomonas major (Berliner) Lemmermann, seus representantes foram encontrados, até o momento, apenas no trato intestinal do lagarto verde Lacerta viridis Gessner. A informação sobre as características ambientais dos locais de onde provieram os exemplares de Petalomonas deste trabalho é muito vaga. Contudo, tais coletas devem ter sido feitas no hidrofitotério do Jardim Botânico de São Paulo ou no Lago das Ninféias, por serem os únicos que contêm exemplares de Salvinia auriculata Aublet. Em qualquer um destes ambientes, há muita quantidade de matéria orgânica autóctone em decomposição. E todos os exemplares de Scytomonas major (Berliner) Lemmermann provieram do plâncton ou das amostras de sedimentos coletadas, jamais do trato intestinal de algum lagarto.

Por fim, conforme afirmado por Bicudo (2009), embora alguns trabalhos mencionem o depósito de material coletado por B.V. Skvortzov no Herbário Científico do Estado "Maria Eneyda P. Kauffmann Fidalgo"(SP), tal fato jamais ocorreu. De fato, Skvortzov coletava os materiais e os mantinha vivos, em cultivos bastante simples, feitos utilizando solo do ambiente de proveniência do material e água de torneira. Tais cultivos eram deixados em sua própria sala de trabalho, à temperatura e luz ambiente, intocados por 10-12 dias, após o que eram examinados ao microscópio. Passando mais tempo, ou a água nesses cultivos secava e o material neles contido se perdia ou os frascos que continham os cultivos eram lavados ante a necessidade de mais recipientes para novos cultivos. De uma ou outra forma, os materiais-tipo de todas as espécies propostas por Boris V. Skvortzov jamais foram depositados em um herbário. No caso específico dos representantes da família Petalomonadaceae, tampouco os materiais são passíveis de fixação e conseqüente preservação.

\section{Agradecimento}

$\mathrm{O}$ autor é imensamente grato ao $\mathrm{CNPq}$, Conselho Nacional de Desenvolvimento Científico e Tecnológico pelo financiamento parcial desta pesquisa (Processo n ${ }^{\circ}$ 303876/2004-2).

\section{Literatura citada}

Berliner, E. 1909. Flagellaten-Studien. Archiv für Protistenkunde 15: 297-325.

Bicudo, C.E.M. 2010. Criptógamos do Parque Estadual das Fontes do Ipiranga, São Paulo, SP. Algas 29: Euglenophyceae (família Peranemaceae). Hoehnea 37(2): 201-220.

Bicudo, C.E.M. \& Bicudo, D.C. 1987. Some new and rare Euglenophyceae from the state of São Paulo, southern Brazil. Acta Botanica Brasilica 1: 43-48.

Bicudo, C.E.M. \& Menezes, M. 2006. Gêneros de algas de águas continentais do Brasil: chave para identificação e descrições. 2 ed. RiMa Editora, São Carlos.

Bourrelly, P. 1970. Les algues d'eau douce: initiation à la systématique: les algues vertes. v. 1. Éditions N. Boubée \& Cie, Paris.

Dobell, C.C. 1908. The structure and life-history of Copromonas subtilis, nov. gen., nov. sp.: a contribution to our knowledge of the Flagellata. Quarterly Journal of Microscopical Science 52: 75-120.

Huber-Pestalozzi, G. 1955. Euglenophyceen. In: Das Phytoplankton des Süsswassers: Systematik und Biologie. E. Schweizerbart'sche Verlagsbuchhandlung (Nägele u. Obermiller), Stuttgart, v. 16(4), pp. 1-606.

Leedale, G.F. 1967. Euglenoid flagellates. PrenticeHall, Englewood Cliffs.

Mignot, J.-P. 1966. Structure et ultrastructure de quelques Euglenomonadines. Protistologica 2: 51-117.

Mignot, J.-P. 1967. Affinités des Euglénomonadines et des Chloromonadines: remarques sur la systématique des Euglenida. Protistologica 3: 25-60.

Skvortzov, B.V. 1968. Flagellata species of genus Petalomonas Stein, Fam. Peranemaceae, Euglenophyta with quadrangular cells recorded in swamp water of São Paulo in mountain subtropical region of Brasil. Acta Botanica Venezuelica 3: 293-296.

Starmach, K. 1983. Euglenophyta, Eugleniny. In: K. Starmach \& J. Siemińska (eds). Flora Słodkowodna Polski v. 3. Państwowe Wydawnictwo Naukowe, Warszawa, Kraków. 